\title{
Draw-A-Science-Comic: Alternative prompts and the presence of danger
}

\author{
Jaakko Lamminpää ${ }^{1}$ and Veli-Matti Vesterinen ${ }^{2}$ \\ ${ }^{1}$ Department of Physics and Astronomy, University of Turku, Finland \\ ${ }^{2}$ Department of Chemistry, University of Turku, Finland
}

The early years of primary school are important in shaping how children see scientists and science, but researching younger children is known to be difficult. The Draw-A-Scientist Test (DAST), in which students are asked to draw a scientist, has been one of the most popular ways to chart children's conceptions of scientists and science. However, DAST tends to focus mainly on children's conceptions about the appearance of scientists. To focus more on children's conceptions of scientific activities as well as the emotions and attitudes associated with science, the DrawA-Science-Comic test (DASC) was recently introduced. This study compares three alternative DASC prompts for two age groups of respondents (8- to 10-year-olds and 10- to 13-year-olds). The prompts asking students to draw a comic or a set of pictures produced significantly more sequential storytelling and depictions of science related emotions and attitudes than the prompt asking students to depict a story. The depictions of elements of danger, such as accidents and hazards in the laboratory, were also frequent in drawings with sequential storytelling. A more detailed analysis of the depictions showed that the frequency of elements of danger was closely associated with depictions of activity especially in the field of chemistry. For example, several comics included failed chemical experiments leading to explosions. Although depictions of danger are sometimes interpreted as a negative conception, in the children's drawings the explosions and overflowing flasks were often seen also as a source of excitement and joy. Based on the result of this study, the use of DASC seems a suitable way for charting children's conceptions of scientific activities as well as the emotions and attitudes associated with science from the early years of primary education until the beginning of secondary education.

Keywords: Draw-A-Scientist Test, DAST, science education, primary school, stereotypes, drawing, misconceptions

\section{Introduction}

If you were asked to picture a scientist, you would most likely think of an older man in lab coat, fizzy hair, safety glasses and chemistry equipment. This is not surprising as it is the predominant way children depict a scientist (Chambers, 1983; Finson, 2002; Miller, Nolla, Eagly, \& Uttal, 2018), and it is so deeply rooted that even teachers and adults hold similar stereotypic views (Losh, 2010; McCarthy, 2015). When questioned further, people might additionally have alternative and more accurate views on scientists (e.g. Finson, Beaver, \& Cramond, 1995), but the stereotype is 
usually the first one to pop into one's mind. At first glance, this might not seem particularly harmful, but it paints a distorted image of science as suitable only for eccentric, old and overly genius men (e.g. Finson, 2002; Reis \& Galvao, 2004) and lonely researchers who have devoted their whole life to science (e.g. Christidou, Bonoti, \& Kontopoulou, 2016). These kinds of conceptions might be the underlying cause why students won't find science interesting or consider taking up a career in sciences (e.g. Archer et al., 2013).

Drawing tasks have been a common method for data collection to study these stereotypes and other conceptions of scientists. One of the most frequently used method has been the Draw-A-Scientist Test (DAST) (see Chang et al., 2020; Finson, 2002; Miller et al., 2018). Drawing is especially useful for studying children as it doesn't require advanced writing or verbal skills (Finson et al., 1995; Prosser \& Burke, 2008), but it has also turned out to be an effective tool for studying older students and adults alike (e.g. McCarthy, 2015; Reinisch, Krell, Hergert, Gogolin, \& Krüger, 2017). The DAST was originally designed to determine when students' drawings begin to exhibit stereotypic indicators of scientists (Chambers, 1983). It has since then been modified by using alternative prompts (e.g. Symington \& Spurling, 1990), revised checklists (e.g. Finson et al., 1995) and evaluation rubrics (e.g. Farland-Smith, 2012). The studies have also focused to address different research questions, such as the effects of ethnicity, culture and gender (Christidou, 2011; Christidou et al., 2016; Miller et al., 2018) as well as the impact of different teaching interventions (Cakmakci et al., 2011; Hillman, Bloodsworth, Tilburg, Zeeman, \& List, 2014; Miele, 2014).

Originally DAST focused on the stereotypic appearance, but lately it has also been used to study students' conceptions of research environments and research activities (e.g. Farland-Smith, 2012; Reinisch et al., 2017). Emvalotis and Koutsianou (2018) have pointed out that students' attitudes towards science are probably more linked to their views about science as an activity than to their conceptions about the appearance of scientists. This in mind, Lamminpää, Vesterinen and Puutio (2020) introduced a new method: the Draw-A-Science-Comic (DASC). It was built on DAST, but the idea was to focus especially to the scientific activities and the related emotions by drawing comics. The results showed that children would be able to express their thoughts about scientists' work better than in DAST by using sequential pictures. However, in their comics children often included dangerous elements and situations, such as explosions when mixing liquids, which might be due to the comic format. This study develops the method introduced in the aforementioned pilot study further by 
evaluating the use of three different prompts. It also explores the way children depict danger in their sequential drawings.

\section{Literature}

\subsection{The influence of the stereotypic image}

A standard or a stereotypic image of scientist plays a crucial role in shaping people's conceptions and attitudes from childhood to adulthood. The stereotypic image develops already during the first years of primary school (Arthur, Bigler, Liben, Gelman, \& Ruble, 2008; Chambers, 1983; DeWitt \& Archer, 2015), and from that point on stereotypes, conceptions and views related to science have a notable impact on children's attitudes towards science (Archer et al., 2013; Christidou, 2011; Dimopoulos \& Smyrnaiou, 2005). This also affects their motivation, interest in the subject, and even school and career choices (Britner, 2008; DeWitt \& Archer, 2015; Fung, 2002). Even greater impact comes from the fact that these views persist firmly to adulthood (Losh, 2010; Rahm \& Charbonneau, 1997), after which the aspirations are unlikely to change dramatically (Aschbacher, Li, \& Roth, 2010; Maltese \& Tai, 2011).

These attitudes can be seen in many developed countries. For example, in Finland a report including over 65 ooo 9 th graders noted that while students acknowledge the importance of natural sciences, they find it uninteresting or even off-putting (Kärnä, Hakonen, \& Kuusela, 2012). Jenkins and Nelson (2005) noticed similar results among secondary school students in England. The phenomenon is peculiar because students still considered science as important and something that 'everybody should learn in school' (Jenkins \& Nelson, 2005; Kärnä et al., 2012). While some students still find science fascinating, in the end, they do not see themselves working as scientists (DeWitt \& Archer, 2015). This leads to a conclusion that the usual way of highlighting the importance of science is not enough to encourage students to pick up a career in sciences.

In addition to the standard image, this can be applied to the stereotypes regarding the scientific activities (cf. Emvalotis \& Koutsianou, 2018) and other aspects, and it is paramount to address these issues at an early age. In order to do so, we must have a wider and deeper understanding of young children's stereotypes and conceptions affecting their attitudes (Campbell, Schwarz, \& Windschitl, 2016; Duit, Gropengießer, 
Kattmann, Komorek, \& Parchmann, 2012; Farland-Smith, Finson, Boone, \& Yale, 2012).

\subsection{The stereotypic image and the modified DAST}

David Chambers (1983) was the first to use drawing as a method to observe when children began to form the stereotypical conception of the appearance of a scientist. In his Draw-A-Scientist Test (DAST), primary school students were asked to 'draw a picture of a scientist' and the instances of indicators for a standard image of a scientist were counted. The standard image could better be described as a stereotype of a scientist as on older Caucasian male with a lab coat, glasses, fizzy hair, and surrounded by chemistry equipment, and it developed during the first four years of elementary school. Later on, researchers have modified the DAST to include additional aspects and to answer alternative research questions. The following summary focuses on the most relevant modifications and studies. For a more detailed history of the (modified) DAST, using drawings as a research instrument, and the related methodical challenges, see studies by Finson (2002), Losh et. al (2008), Reinisch et. al (2017), and Chang et. al (2020).

Symington and Spurling (1990) compared the original prompt ('Draw a picture of a scientist') to a new one: 'do a drawing which tells me what you know about scientists and their work'. Although some children produced similar depictions with both instructions, the majority did not. The inclusion of participants' own beliefs and the differences in the drawings indicated that children might hold alternative views but are inclined to draw the stereotype when the traditional prompt is used. The prompt is guiding the focus to scientists' work and not just the appearance. In a similar fashion, the impact of the prompt has been noted and utilized for alternative research foci, like conceptions related to scientists in different fields of science (e.g. Hansen et al., 2017; Oktay \& Eryurt, 2012).

In 2003, Donna Farland introduced the modified DAST, which included a revised prompt and a new rubric to evaluate the drawings (Farland-Smith, 2012). She had a more detailed prompt asking the participants to imagine scientists working, draw them busy with work, and add captions what they are saying or doing. The pictures were evaluated for the level of accuracy in three different categories: appearance (what scientists look similar to), location (where scientists work), and activity (what scientists do). Including activity into the evaluation was a step towards better understanding children's views and attitudes towards science. As recent studies show, 
the attitudes are more related to conceptions of what scientists do instead of what they look like (Christidou et al., 2016; Emvalotis \& Koutsianou, 2018).

Scientific activities are difficult to portray in a single picture (see Reinisch et al., 2017), which led to the development of the Draw-A-Science-Comic test (DASC) (Lamminpää et al., 2020). The test was based on the modified DAST, but instead of using a single picture, the participants were asked to draw a comic. With a comic the participants could depict activities, human interaction, emotions, and tell a story through sequential pictures (cf. Eisner, 2008; Kress, 2010; Kuttner, Sousanis, \& Weaver-Hightower, 2017). The prompt was designed as open as possible (see Reinisch et al., 2017), and the participants received only the prompt: 'Draw a comic about how you think science is done'. ${ }^{1}$ The results showed that almost every comic depicted scientific activities, such as different phases of research, solving problems, and discussing or evaluating results. Furthermore, many comics showed an affective side of science, such as frustration and anger due to failed experiments, astonishment of chemical reaction and joy of a successful task (cf. Hsieh \& Tsai, 2017). However, DAST seemed to be more suited to observe the appearance and the location. Lamminpää and his colleagues (2020) also noted a significant amount of dangerous elements and situations, such as explosions after mixing chemicals, when compared to DAST. In light of these findings, they suggested testing alternative prompts to study the impact of the comic format.

\subsection{The critique of DAST and drawing instruments}

Despite being popular, drawing as a research instrument has also received a fair amount of critique. For example, when prompted to draw another scientist, some children tend to draw a character that is vastly different from their earlier depiction. This has lead researchers to conclude that children can hold multiple conceptions of scientists (e.g. Losh et al., 2008; Maoldomhnaigh \& Hunt, 1988). Finson and Pederson (2011) even stated that children's presentations often differ from the views they express in interviews. They argued that drawing assignments might encourage the children to draw pictures they think are easily recognizable to the viewer. While this might be true, charting the stereotypes still holds value. Even if the students do not fully believe their depicted stereotypes to be factual, the portrayal of stereotypes shows the children are at least aware of them, and such awareness might affect their

\footnotetext{
${ }^{1}$ Translated from Finnish.
} 
attitudes towards science. However, all drawings are subjected to interpretations, and as such, it is difficult to explicitly connect different aspects in drawings to conceptions or attitudes of individual students (Losh et al., 2008). This is especially important when interpreting symbols that might hold multiple or even hidden meanings (Ball \& Smith, 1992; Reinisch et al., 2017). Furthermore, the children's ability or willingness to depict their conceptions has been criticised (e.g. Yuen, 2004). While drawing does not require verbal or written answers, children have limited drawing abilities and they might struggle to convey their ideas through drawings.

To address the aforementioned challenges it has been suggested, that additional data gathering methods should be utilized to verify researchers' interpretations and to assign meaning to drawn items (e.g. Reinisch et al., 2017). Thus several studies have used additional questionnaires and interviews to triangulate children's thoughts more accurately (e.g. Ehrlen, 2009; Hillman et al., 2014; Reinisch et al., 2017). Questionnaires and interviews can be considered appropriate for older students and adults (McCarthy, 2015; Reinisch et al., 2017), but younger children may harbour stereotypes before being able to express them explicitly (Galdi, Cadinu, \& Tomasetto, 2014). Therefore, the use of indirect measurements, such as drawing, might be more effective for younger children than verbal or written methods (Cvencek \& Meltzoff, 2015; Losh et al., 2008). Similarly, Chang and colleagues (2020) summarized in their systematic review four main justifications for using drawings as a research tool: a) an alternative to overcome the young participants verbal and writing abilities, b) a method to reveal aspects not easily recognized with other methods, c) a major method that reflects characteristics of science subjects and (d) a formative assessment to diagnose students' ideas to benefit their learning.

\section{Rationale and research questions}

This study continues the development of the Draw-A-Science-Comic test (DASC). In DASC the children are able to depict especially their conceptions of scientific activities and emotions related to science through sequential pictures (Lamminpää et al., 2020). However, the prompt might affect the way children depict science and research (e.g. Symington \& Spurling, 1990). For example, in DASC the word 'comic' in the prompt might invite children to draw unwanted accidents and dangerous situations. The goal of this study was to test alternative prompts and their effect on the children's depictions of science and scientists while maintaining the sequential story-telling format. A more detailed description of the different categories and the analysis is 
presented in the method section. Three different DASC prompts were used and their impact on the depictions of science was compared. As the data was collected from two different age groups, the differences between the age groups were also analysed. The research questions were:

1. How do the alternative prompts for the Draw-A-Science-Comic test (DASC) affect the frequency of sequential storytelling as well as the frequency of depictions of appearance, location, activity, emotions and attitudes, and elements of danger?

2. How children's age affects the frequency of sequential storytelling as well as the frequency of depictions of appearance, location, activity, emotions and attitudes, and elements of danger.

To further understand the results of the first round of analysis, the results in each category were compared with other categories. The closer analysis revealed that the elements of danger were associated with activities and especially with laboratory work in chemistry. Thus, the second round of analysis focused on the depictions of elements of danger and sought to answer two interconnected research questions which were:

3. How elements of danger were depicted in a sequential format?

4. How prevalent were the depictions of elements of danger in the most frequently depicted fields of science?

\section{Method}

\subsection{Design of the prompts}

The Draw-A-Science-Comic test uses the prompt 'Draw a comic about how you think science is done' (Lamminpää et al., 2020). The prompts used in the study were in Finnish and prompts presented here are translations of the prompts. The idea of DASC is to invite the children to draw sequential pictures and enable them to tell a story about how scientists work through a wide array of different modes of communication (see Lamminpää et al., 2020). Two alternative prompts with the same aim were designed for this study. The first revised prompt replaced the word 'comic' with the word 'story' and the second revised prompt used the phrasing 'set of pictures'. Both prompts have a similar purpose as the comic and they invite to tell a story through multiple frames and sequential storytelling. The complete prompts are 
presented in Table 1.

Table 1. Participants and their age group for each prompt.

\begin{tabular}{lll}
\hline Prompt & Age & Participants \\
\hline Draw a comic about how you think science is made & $8-10$ & 37 \\
& $10-13$ & 36 \\
Draw a story about how you think science is made & $8-10$ & 40 \\
Draw a set of pictures about how you think science is made & $10-13$ & 28 \\
\hline
\end{tabular}

\subsection{Participants and data collection}

The data was collected from 180 children attending the science camps of a Finnish university during summer 2018. The summer camp participants were chosen randomly from those who applied. The main topics for the camps were physics and astronomy, nature science (biology and chemistry), and robotics. The camps were organized for two separate age groups (8-10 year-olds and 10-13 year olds) which allowed us to compare the effects on different age groups. However, we had 5 test groups which consisted of 2 younger and 3 older groups. As we considered the set of pictures task to be less tangible, it was chosen to be drawn only by the older participants. The DASC was administered before the camps started during the info session and the prompts included roughly equal distribution of participants from all camp themes. By request of the organizers, no personal data was gathered to ensure the anonymity of the children. According to the guidelines set by the Finnish National Board of Research Integrity TENK (Kohonen, Kuula-Luumi, \& Spoof, 2019) consent to participate was obtained from the children as well as their parents. The number of participants for both age groups are presented in the Table 1.

The data was collected before the science camp started, but the children were most likely influenced by their expectations about the upcoming camp. This increases the probability to include these ideas in their drawings. In addition, it should be taken into account that children taking part in science camp are also most likely more interested and better informed about science than their peers on average. Thus, we refrain from making generalisations about the prevalence of the views depicted. 


\subsection{Method of analysis}

During the first phase each drawing was analysed using four main categories. These mutually non-exclusive categories included the depictions about the (i) appearance of scientists, (ii) locations of research, (iii) research activities, and (iv) emotions and attitudes related to science and research. The definitions for each category are intuitive and include depictions and information of the category (see Lamminpää et al., 2020). The exact nature of these depictions, however, is not included in the analysis due to the lack of supporting data gathering methods, and the aim of this study is to focus on the effect of the different prompts. As the use of sequential storytelling is the central characteristics of DASC, the instances of sequential stories were also calculated. Non-sequential drawings included both single DAST-like pictures as well as collections of separate pictures that did not tell a linear story (cf. Reinisch et al., 2017). One of observation of the initial DASC study (Lamminpää et al., 2020) was that elements of danger seemed to be rather prevalent in DASC drawings. Therefore, the instances of elements of danger were also included in the analysis. The Chi-squared test was used to calculate the significance of differences between the original DASC task and the two alternative tasks. To ensure the reliability of the analysis, all drawings were independently analysed by two coders. To measure the inter-rater reliability during the first phase of analysis, Cohen's Kappa was calculated for each category. After this, the differences in the analysis were discussed until a consensus was reached.

As an example of the first phase of the analysis, we present a comic drawn by a 10to 13-year-old (Figure 1). The comic consists of three separate sequential depictions of scientists doing research in the fields of astronomy, chemistry and biology. In the first one, a person is observing stars with a telescope. The second part shows how mixing wrong liquids leads to an explosion or the mixture pouring over. The experiment still seems to yield a new scientific finding. The last depiction shows a researcher finding a flower. When she cannot find the description of the species in a book, she comes to a conclusion that she has found a new species. Even though the comic portrays scientists as stick figures, it still includes variation in the depictions of the appearance of scientists. For example, only one of the scientists-the astronomer-had glasses. The comic included also depictions of several locations of research as well as research activities. 


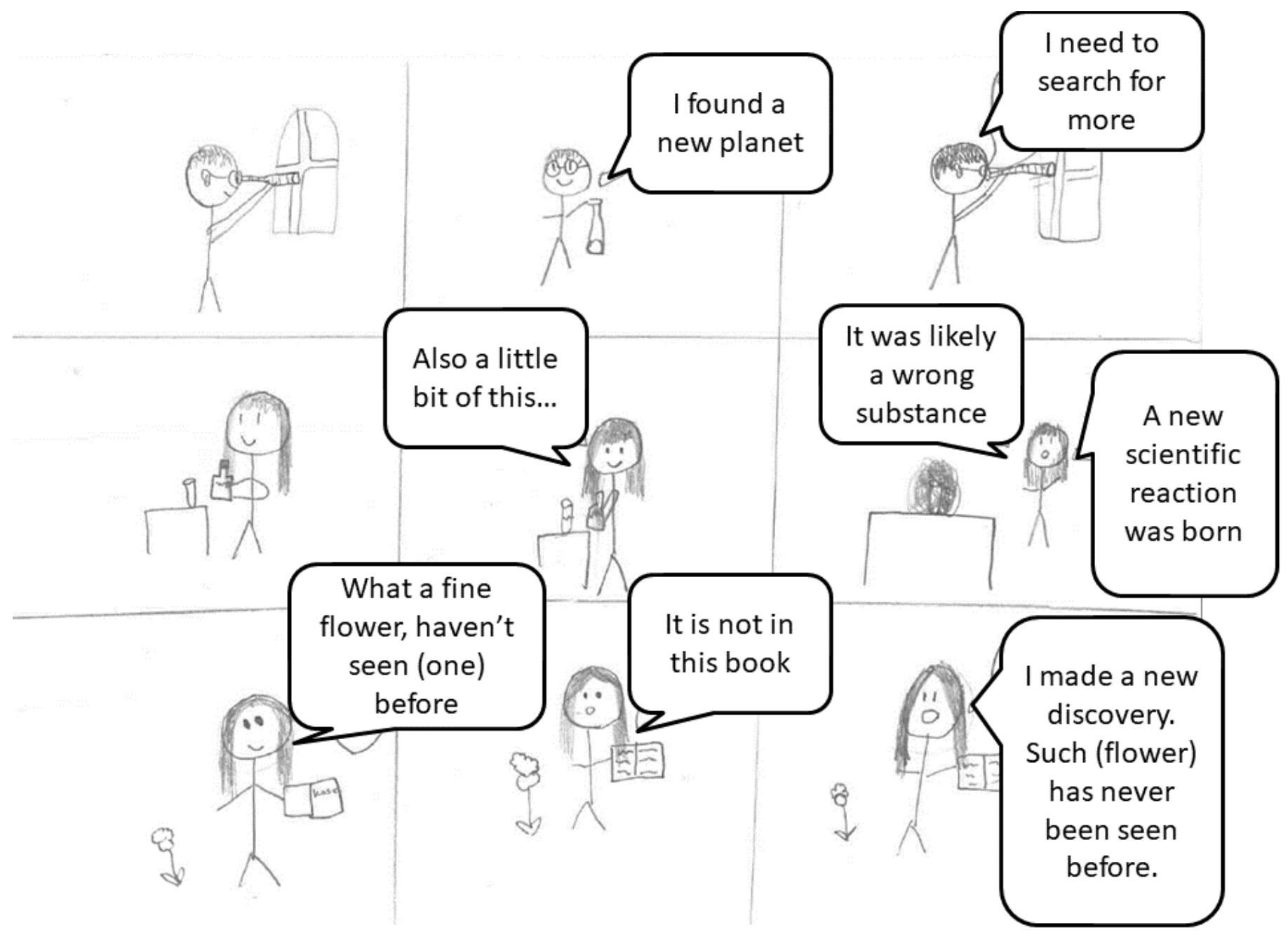

Figure 1. A comic with three strips depicting different scientific research activities.

The text is translated from Finnish.

By comparing the results in each category of analysis with others, it was noticed, that the depictions of elements of danger were related to the depictions of activity. To provide a better overview of how the activities and dangers were related, the elements of danger were further categorized into two inductively formed categories. In this second phase of analysis, each element of danger was categorized either as a part of the activity, such as an explosion resulting from mixing liquids, or as a static symbol of danger, such as a warning sign.

During the closer analysis of the depictions of elements of danger, it was also noticed, that most of the elements of danger seemed to be connected with depictions of chemical laboratory experiments. To evaluate the significance of this observation, different activities were categorized based on the fields of science depicted in the drawing. The categories were again formed inductively. The most often depicted fields of science included chemistry, biology, space research and robotics. Some of the 
drawings included multiple activities with different fields of science (see Figure 1). The Chi-squared test was used to calculate the statistical significance of the differences in the frequency of the elements of danger associated with each recognized field of science. As an example of a drawing depicting danger associated with chemistry, the story from an 8- to 10-year-old depicts a female scientist with a lab coat and safety glasses mixing liquids in a laboratory (Figure 2). In this drawing, the danger was clearly part of the activity. The story also included depictions of emotions related to scientific research. The story begins with frustration caused by constant explosions. After a while the researcher tries again, changes clothes and is seemingly happier. However, another explosion follows, causing some disorientation or confusion, which leads to boiling anger and a packed suitcase. The story ends with a phrase 'I quit'.
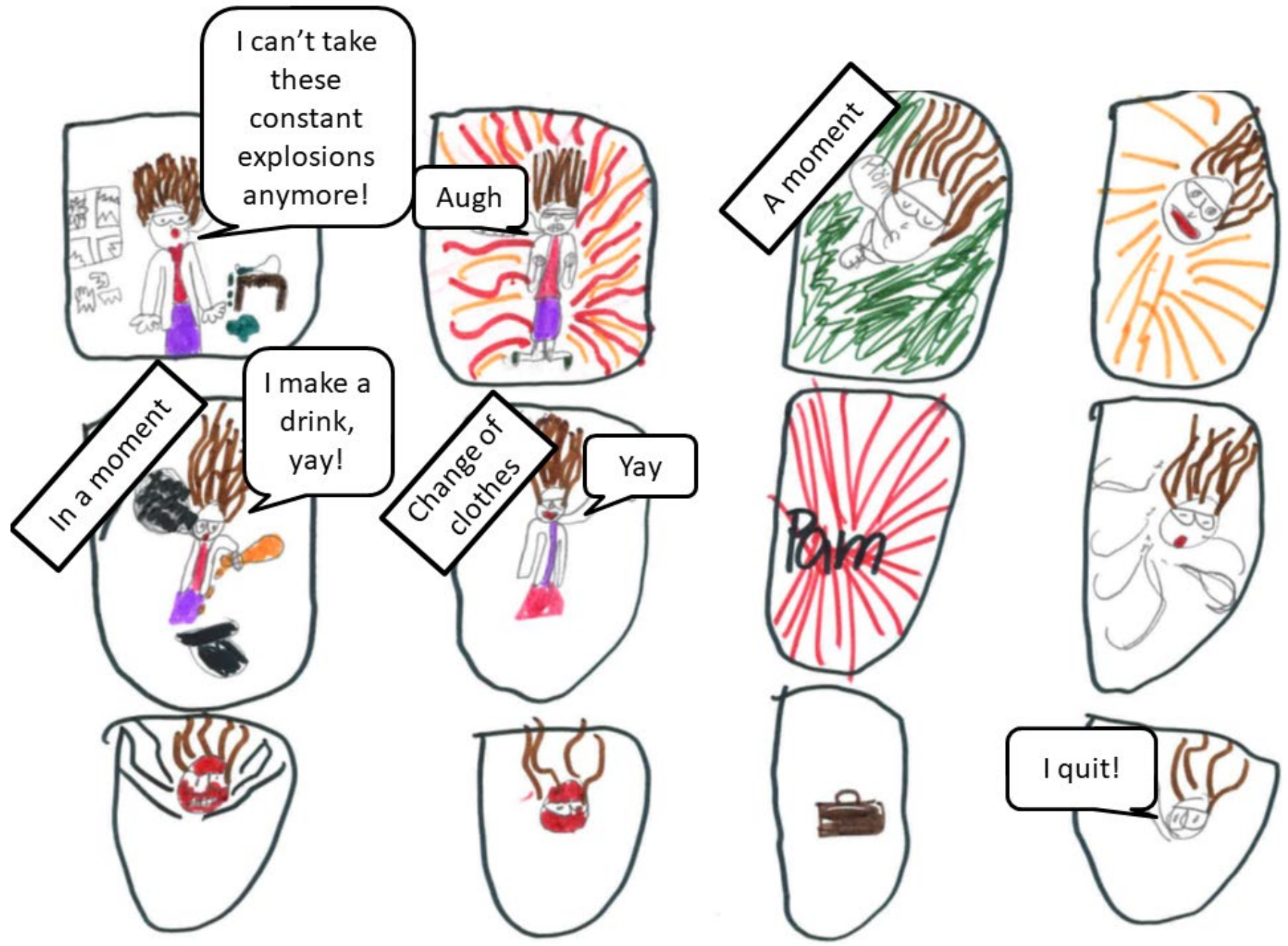

Figure 2. A story depicting a female scientist becoming fed up with explosions and quitting her job. The text is translated from Finnish. 


\section{Results}

Regardless of the prompt used, most drawings (88 \%) included depictions of activity. With all three prompts the depictions of locations and appearances were less frequent than depictions of activities. The frequencies of depictions of activity, emotions and attitudes, and elements of danger were consistently higher in the older age group than in the younger age group. The results of the first round of analysis for each prompt and age group are presented in Table 2.

Table 2. Percentages of different categories for each prompt and age group. For statistical significance ${ }^{*} p<.05$ and ${ }^{* *} p<.005$ when compared to the comic prompt. The inter-rater reliability measured with Cohen's Kappa is presented in last column.

\begin{tabular}{|c|c|c|c|c|c|c|c|}
\hline \multirow[t]{2}{*}{ Categories } & \multicolumn{2}{|l|}{ Comic } & \multicolumn{2}{|l|}{ Story } & \multicolumn{2}{|l|}{$\begin{array}{l}\text { Set of } \\
\text { pictures }\end{array}$} & \multirow[t]{2}{*}{$\begin{array}{l}\text { Cohen's } \\
\text { Kappa }\end{array}$} \\
\hline & Younger & Older & Younger & Older & Older & Total & \\
\hline Appearance & .35 & .50 & .40 & .36 & $.26^{*}$ & .37 & .90 \\
\hline Location & .46 & .75 & .68 & .61 & .77 & .66 & .84 \\
\hline Activity & .73 & .94 & .80 & .96 & .97 & .88 & .85 \\
\hline Emotions and & & & & & & & \\
\hline attitudes & .41 & .58 & $.20^{*}$ & $.29 *$ & .44 & .38 & .89 \\
\hline Sequential storytelling & .86 & .94 & $.58 * *$ & $.50 * *$ & .95 & .78 & .95 \\
\hline Elements of danger & .22 & .53 & .20 & .36 & $.23^{*}$ & .30 & .86 \\
\hline
\end{tabular}

The comic and story prompts were used in data collection for both age groups. When the results of the analysis these two prompts were compared, there were no statistically significant differences in most categories of analysis (see Table 2). Statistically significant differences were seen in two categories of analysis. In both age groups, the story prompt provided significantly less depictions of emotions and attitudes, $\chi^{2}(1, N=77)=3.87, p=.05$ for younger and $\chi^{2}(1, N=64)=5.63, p=.02$ for older, as well as drawings that used sequential storytelling, $\chi^{2}(1, N=77)=7.91$, $\mathrm{p}=.05$ and $\chi^{2}(1, \mathrm{~N}=64)=16.59, \mathrm{p}=.001$ respectively.

The set of pictures prompt was used only for the older age group. Again, for most categories of analysis, there were no statistically significant differences between the set of pictures and comic prompts (see Table 2). Both prompts produced a relatively high proportion of drawings using sequential storytelling. The set of pictures prompt produced less drawings with depictions of emotions and attitudes, but the difference was not statistically significant, $\chi^{2}(1, N=75)=1.63, p=.20$. Statistically significant differences were found in the frequency of the depictions of appearance $\chi^{2}(1, N=75)$ 
$=4.75, \mathrm{p}=.03$ and elements of danger $\chi^{2}(1, \mathrm{~N}=75)=7.06, \mathrm{p}=.008$. When the categories of analysis were compared with each other, it could be seen that the drawings depicting activities had significantly more depictions of elements of danger than other drawings $\chi^{2}(1, N=180)=7.73, p=.005$. There were also slightly more depictions of emotions in drawings with depictions of elements of danger. However, the difference was not statistically significant $\chi^{2}(1, N=180)=1.22, p=.27$.

The depictions of elements of danger were usually the repercussions of the research and portrayed through sequential pictures. For example, in chemistry the mixing of two substances preceded the reaction which was then observed as an explosion or a rapid overflowing of the mixture. Altogether, in $89 \%$ of all depictions of danger, the danger was depicted as a part of an activity and only six out of the 54 dangerous elements depicted (11\%) were traditional static warning signs such as warning labels. The emotions depicted in connection with elements of danger included varying emotions, such as joy, surprise, fear and bewilderment.

Each prompt provided depictions of research on various fields of science. For these categories of analysis there were no statistically significant differences between the different prompts. The most common field of science depicted in the drawings were chemistry (101), biology (33), astronomy (30) and robotics (13). The dangerous elements were predominantly related to chemistry, $\chi^{2}(1, N=177)=28.50, p<.001$, and $87 \%$ of all elements of danger were portrayed in drawings including chemistry activities. These depictions consisted mostly of explosions or rapid reactions resulting in overflowing flasks. These explosions could not directly be associated with fear and they often included emotions such as joy and bewilderment. In contrast, drawings with biology were depicted as significantly less dangerous than other fields of science $(p=.004)$ and included only two depictions of danger. Even in these two cases the depictions of danger were part of chemistry laboratory activities.

\section{Discussion}

As expected, the frequency of depictions in all categories of analysis increased with age (see Table 2) and this supports the findings of DAST and drawing related studies. Firstly, the stereotypes and conceptions develop during the first years of primary school (e.g. Chambers, 1983). The older children have a more exact or refined conceptions of science and other categories and thus they can provide more information about these categories. At the same time, older children tend to have better drawing abilities and are able to express themselves better through drawings 
(cf. Jolley, Fenn, \& Jones, 2004). Despite the use of labels and written text, younger children might leave out information they are unable to draw. However, the use of indirect and implicit measurements might be more effective than written or verbal responses (Cvencek \& Meltzoff, 2015). The challenging nature of studying children's conceptions and the complex nature of these conceptions makes it impossible to attribute the results solely to either of these factors.

For all prompts the depictions of appearance of scientists and location of research were considerably less frequent than depictions of activities. Based on the results of this study, the DASC format seems to offer no clear advantage in examining the conceptions regarding the appearance of the scientist or the research locations when compared to the traditional or modified DAST (cf. Chambers, 1983; Emvalotis \& Koutsianou, 2018; Fung, 2002).

Almost all prompts provided drawings with frequent descriptions of scientific activities. However, the drawings collected using the story prompt were more often non-sequential and bore resemblance to the traditional DAST. Sequential storytelling, inherent to comic format, is especially suited to the description of action and activities (see Eisner, 2008; McCloud, 1994). Drawings using only a single picture to describe the activity can be more prone for misinterpretations as the activity has to be deciphered from the context of the picture without further information about the activity, such as how the depicted instruments are used (see Reinisch et al., 2017). Thus, the use of the comics and the set of pictures prompts seem more suited than the story prompt or the traditional DAST for charting students conceptions of scientific activities and the process of doing science.

Depictions of emotions and attitudes were more frequent when using the comics prompt than the other two prompts. However, the difference was statistically significant only compared with the story prompts (see Table 2). As emotions are often based on a stimulus and a response, sequential storytelling can be used to illustrate situations that provoke emotions. Thus, sequential drawings such as comics are well suited for depicting how scientific activities evoke emotions, such as frustration caused by a failed experiment. Measuring the exact nature of the emotions and attitudes expressed in the drawings was not in the scope of this study, and in the future, it would be beneficial to try to categorize and link the emotions in the drawings to children's attitudes towards science by using additional data gathering methods focusing on children's views about science and scientific inquiry (see Johnson \& Onwuegbuzie, 2011; Lederman et al., 2014; Walls, 2012). 
As suggested by Lamminpää and his colleagues (2020), the children might be more prone to present elements of danger when asked to draw a comic. In DAST the elements of danger are usually warning signs or labels but in DASC the elements of danger were mostly depicted sequentially as part of an activity. However, it is not selfevident that seemingly dangerous situations such as liquids shooting out of containers should be considered as dangerous. They can also be the desired result of the experiment and not a dangerous accident. This interpretation is supported by multiple comics showing bewilderment and joy after the experiment with captions like 'wow'. In contrast, the traditional warning signs and labels occurring in the DAST might be considered as more distinct indications of danger. However, Fu and her colleagues (2015) pointed out that even these can also be related to safety precautions learnt at school and, therefore, might not illustrate the actual perceived danger. The problem with the current method is that it might not reveal actual conceptions of danger and its relation to the drawing. The other common factor among the elements of danger is the portrayed activity. Most dangerous elements were related to chemistry whereas biology was always depicted as a safe activity.

Regardless of the prompt, the occurrences of dangerous elements, such as explosions, were still considerably more frequent than in the DAST studies (cf. Emvalotis \& Koutsianou, 2018; Türkmen, 2008). The elements of danger depicted were usually portrayed through sequential pictures as the repercussion of the research activity. For example, in chemistry, the mixing of two substances preceded the reaction which was then observed as an explosion or a rapid overflowing of the mixture. This shouldn't be surprising as many polls and questionnaires indeed show that many people consider scientific work as dangerous or at least are worried by the potential risks (cf. Edwards, Ceci, \& Ratcliffe, 2016; National Science Board, 2002). On the other hand, the static warning labels were observed only in few drawings and the number is more in line with the aforementioned DAST studies. To ensure the actual meaning and reason for drawing the explosion, we recommend interviewing children because the drawings do not necessarily depict actual conceptions of danger. Moreover, as the depictions of danger were much more frequent when depicting chemical research than other fields of science, the conception of science as something dangerous seems to be associated mainly with the chemical sciences. Thus, generalisations about children's conceptions about the elements of danger in science in general should not be made from a single drawing. 
While drawings included variety of scientific activities from hypothesizing and analysing to experimenting and discussing science, the main emphasis in the depictions was on research through experimentation and observations within the context of chemistry, biology, and astronomy. Unsurprisingly, the most usual conception of scientific activities are related to research and its various aspects (see Emvalotis \& Koutsianou, 2018; Reinisch et al., 2017). However, Hsieh and Tsai (2018) observed that children consider that learning science happens mainly through teacher oriented classes. This was also observed in drawings showing classroom environment and lecturing. Our analysis did not differentiate between doing science in school or actual scientists working, and the drawings depicted both real scientists and children doing science while some of the characters could not be label as either. In the future, it might be beneficial to differentiate between children doing or learning science and actual scientists working.

Before making conclusions we wish to point out some observations and limitations. Firstly, when making inferences based on the p-values, they should not be used as definitive proof but more as incremental evidence (see Baker, 2016; Vidgen \& Yasseri, 2016). To increase the reliability of the inferences made, triangulation with additional data gathering methods should be used whenever possible. As no additional data gathering methods, like interviews, were in this study the interpretations of the elements in drawings are debatable to some extent despite the Cohen's Kappa values. Lastly, the participants had most likely a positive bias towards science and they were affected by the upcoming camp, which is why we refrain from making generalisations about the prevalence of the conceptions.

\section{Conclusions}

The aim of this study was to test alternative prompts and their effect on children's drawings of science while providing a sequential picture format. From the three prompts the comic and the set of pictures offer a suitable instrument to observe students' conceptions of the scientific activities and the related emotions and attitudes. The story prompt, on the other hand, resulted often in non-sequential drawings more similar to DAST. In line with the previous DASC study (Lamminpää et al., 2020), the effectiveness comes from the sequential pictures that describe the activities and the use of instrumentation more explicitly than a single picture (cf. Reinisch et al., 2017). Similarly sequence is often needed to express emotions which are usually a response to events or situations (see Lamminpää et al., 2020). In 
contrast, the DASC and different formats seem to offer no advantage to examine the appearance of the scientist or the location where the scientists work when compared to the traditional or modified DAST. The differences between the age groups could be attributed either or both to the development of conceptions during primary school ages or the improved drawing ability (cf. Jolley, Fenn, and Jones 2004; Chambers 1983).

The comics and the set of picture drawings both included more dangerous elements than the DAST (cf. Emvalotis \& Koutsianou, 2018; Türkmen, 2008) and highlight how the dangerous elements are connected to the activity instead of static warning labels. However, the occurrence of dangerous elements was higher in the comics. While the prompt might be responsible, other factors such as the activity and field of science were observed to affect the occurrence of danger. For example, the majority of dangerous elements were depicted as part of chemistry related activities. However, it does not necessarily mean that children see chemistry as dangerous. Firstly, the dangerous situations are our interpretation, and for children the liquid shooting out from a flask might be the intended, controlled and safe result. Secondly, the dangerous elements were often seen as exhilarating and inspiring instead of causing worry or fear. The exact nature of these depictions and the connection to attitudes cannot be determined without additional questionnaires or interviews (see Reinisch et al., 2017) and further research is required. Whereas many people consider science dangerous (e.g. National Science Board, 2002), based on the results we propose that researchers would instead focus on specific fields of science. Describing natural sciences as a whole is not viable if the conceptions and stereotypes differ wildly across different fields of science. For teaching practices this implies that it is paramount to distinguish different fields of science when discussing and addressing stereotypes or misconceptions.

As almost every activity was related to research, we propose that in the future the prompt could be changed to explicitly focus how scientists do research. This might be beneficial for the younger children by being more concrete and ruling out portrayals of students learning themselves (see Hsieh \& Tsai, 2018). As an alternative, it would be interesting to study how children see themselves doing science. However, the repeating portrayal of research indicates that children might not be aware of other aspects of scientific work. The prompt could also be modified to focus on different fields of science. This could help us to better understand how conceptions and stereotypes differ between fields of science. 
This study did not include triangulation by using additional data gathering techniques. To have a more accurate understanding of children's drawings and conceptions behind them, additional questionnaires or interviews should be used as has been done in modified DAST (e.g. Hillman et al. 2014; Reinisch et al. 2017). An open interview in which children explain their drawings would help researchers in making interpretations and offer the possibility to link drawings to actual conceptions and attitudes (see Losh et al., 2008). For example, this would allow verifying if the explosions are truly considered dangerous.

\section{References}

Archer, L., DeWitt, J., Osborne, J., Dillon, J., Willis, B., \& Wong, B. (2013). "Not girly, not sexy, not glamorous": Primary school girls' and parents' constructions of science aspirations.

Pedagogy, Culture and Society, 21(1), 171-194.

https://doi.org/10.1080/14681366.2012.748676

Arthur, A. E., Bigler, R. S., Liben, L. S., Gelman, S. A., \& Ruble, D. N. (2008). Gender Stereotyping and Prejudice in Young Children: A developmental intergroup perspective. In S. R. Levy \& M. Killen (Eds.), Intergroup attitudes and relations in childhood through adulthood. (pp. 6686). New York, NY, US: Oxford University Press.

Aschbacher, P. R., Li, E., \& Roth, E. J. (2010). Is science me? High school students' identities, participation and aspirations in science, engineering, and medicine. Journal of Research in Science Teaching, 47(5), 564-582. https://doi.org/10.1002/tea.20353

Baker, M. (2016). Statisticians issue warning over misuse of P values. Nature, 531(7593), 151-151. https://doi.org/10.1038/nature.2016.19503

Ball, M., \& Smith, G. (1992). Analyzing Visual Data. Thousand Oaks, California. https://doi.org/10.4135/9781412983402

Britner, S. L. (2008). Motivation in high school science students: A comparison of gender differences in life, physical, and earth science classes. Journal of Research in Science Teaching, 45(8), 955-970. https://doi.org/10.1002/tea.20249

Cakmakci, G., Tosun, O., Turgut, S., Orenler, S., Sengul, K., \& Top, G. (2011). Promoting an inclusive image of Scientists among Students: Towards research evidence-based practice. International Journal of Science and Mathematics Education, 9(3), 627-655. https://doi.org/10.1007/s10763-010-9217-4

Campbell, T., Schwarz, C., \& Windschitl, M. (2016). What we call misconceptions may be necessary stepping-stones toward making sense of the world. Science and Children, 53(7), 28-33.

Chambers, D. W. (1983). Stereotypic images of the scientist: The draw-a-scientist test. Science Education, 67(2), 255-265. https://doi.org/10.1002/sce.3730670213

Chang, H. Y., Lin, T. J., Lee, M. H., Lee, S. W. Y., Lin, T. C., Tan, A. L., \& Tsai, C. C. (2020). A systematic review of trends and findings in research employing drawing assessment in science education. Studies in Science Education, 56(1), 77-110. https://doi.org/10.1080/03057267.2020.1735822

Christidou, V. (2011). Interest, attitudes and images related to science : Combining students' voices with the voices of school Science, teachers, and popular science. International Journal of Environmental Science Education, 6(2), 141-159. 
Christidou, V., Bonoti, F., \& Kontopoulou, A. (2016). American and Greek Children's Visual Images of Scientists: Enduring or Fading Stereotypes? Science and Education, 25(5-6), 497522. https://doi.org/10.1007/s11191-016-9832-8

Cvencek, D., \& Meltzoff, A. N. (2015). Developing implicit social cognition in early childhood: Methods, phenomena, prospects. In S. Flannery Quinn \& S. Robson (Eds.), The Routledge international handbook of young children's thinking and understanding (pp. 43-53). Abingdon, England: Routledge.

DeWitt, J., \& Archer, L. (2015). Who Aspires to a Science Career? A comparison of survey responses from primary and secondary school students. International Journal of Science Education, 37(13), 2170-2192. https://doi.org/10.1080/09500693.2015.1071899

Dimopoulos, K., \& Smyrnaiou, Z. (2005). Factors related to students' interest in science learning. In D. Koliopoulos \& A. Vavouraki (Eds.), Science Education at Cross Roads: Meeting the Challenges of the 21st Century (pp. 135-142). Athens: Association for Science Education.

Duit, R., Gropengießer, H., Kattmann, U., Komorek, M., \& Parchmann, I. (2012). The Model of Educational Reconstruction - A Framework for Improving Teaching and Learning Science. In D. Jorde \& J. Dillon (Eds.), Science Education Research and Practice in Europe: Retrospective and Prospective (pp. 13-37). Rotterdam: SensePublishers. https://doi.org/10.1007/978-94-6091-900-8_2

Edwards, J., Ceci, C., \& Ratcliffe, E. (2016). What the Public Really Thinks About Chemistry. Chemistry International, 38(3-4), 16-19. https://doi.org/10.1515/ci-2016-3-406

Ehrlen, K. (2009). Drawings as representations of children's conceptions. International Journal of Science Education, 31(1), 41-57. https://doi.org/10.1080/09500690701630455

Eisner, W. (2008). Graphic Storytelling and Visual Narrative. New York: W. W. Norton \& Company.

Emvalotis, A., \& Koutsianou, A. (2018). Greek primary school students' images of scientists and their work: has anything changed? Research in Science and Technological Education, 36(1), 69-85. https://doi.org/10.1080/02635143.2017.1366899

Farland-Smith, D. (2012). Development and field test of the modified Draw-a-Scientist Test and the Draw-a-Scientist Rubric. School Science and Mathematics, 112(2), 109-116. https://doi.org/10.1111/j.1949-8594.2011.00124.x

Farland-Smith, D., Finson, K., Boone, W. J., \& Yale, M. (2012). An Investigation of Media Influences on Elementary Students' Representations of Scientists. Journal of Science Teacher Education, 25(3), 36-40. https://doi.org/10.1007/s10972-012-9322-Z

Finson, K. D. (2002). Drawing a Scientist: What We Do and Do Not Know After Fifty Years of Drawings. School Science and Mathematics, 102(7), 335-345. https://doi.org/10.1111/j.1949-8594.2002.tb18217.x

Finson, K. D., Beaver, J. B., \& Cramond, B. L. (1995). Development and field test of a checklist for the draw-a-scientist test. School Science and Mathematics, 95(4), 195-205.

https://doi.org/10.1111/j.1949-8594.1995.tb15762.x

Finson, K., \& Pederson, J. (2011). What are Visual Data and What Utility do they have in Science Education? Journal of Visual Literacy, 30(1), 66-85. https://doi.org/10.1080/23796529.2011.11674685

Fu, E., Fitzpatrick, A., Connors, C., Clay, D., Toombs, B., Busby, A., \& O’Driscoll, C. Public attitudes to chemistry, Royal Society of Chemistry $§$ (2015).

Fung, Y. Y. H. (2002). A Comparative Study of Primary and Secondary School Students' Images of Scientists. Research in Science \& Technological Education, 2O(2), 199-213. https://doi.org/10.1080/0263514022000030453 
Galdi, S., Cadinu, M., \& Tomasetto, C. (2014). The Roots of Stereotype Threat: When Automatic Associations Disrupt Girls' Math Performance. Child Development, 85(1), 250-263. https://doi.org/10.1111/cdev.12128

Hansen, A. K., Dwyer, H. A., Iveland, A., Talesfore, M., Wright, L., Harlow, D. B., \& Franklin, D. (2017). Assessing Children's Understanding of the Work of Computer Scientists. In Proceedings of the 2017 ACM SIGCSE Technical Symposium on Computer Science Education - SIGCSE '17 (pp. 279-284). New York, New York, USA: ACM Press. https://doi.org/10.1145/3017680.3017769

Hillman, S. J., Bloodsworth, K. H., Tilburg, C. E., Zeeman, S. I., \& List, H. E. (2014). K-12 Students' Perceptions of Scientists: Finding a valid measurement and exploring whether exposure to scientists makes an impact. International Journal of Science Education, 36(15), 2580-2595. https://doi.org/10.1080/09500693.2014.908264

Hsieh, W. M., \& Tsai, C. C. (2017). Exploring students' conceptions of science learning via drawing: a cross-sectional analysis. International Journal of Science Education, 39(3), 274-298. https://doi.org/10.1080/09500693.2017.1280640

Hsieh, W. M., \& Tsai, C. C. (2018). Learning illustrated: An exploratory cross-sectional drawing analysis of students' conceptions of learning. Journal of Educational Research, 111(2), 139150. https://doi.org/10.1080/00220671.2016.1220357

Jenkins, E. W., \& Nelson, N. W. (2005). Important but not for me: students' attitudes towards secondary school science in England. Research in Science \& Technological Education, 23(1), 41-57. https://doi.org/10.1080/02635140500068435

Johnson, R. B., \& Onwuegbuzie, A. J. (2011). Mixed Methods Research: A Research Paradigm Whose Time Has Come. Educational Researcher, 33(7), 14-26.

Jolley, R. P., Fenn, K., \& Jones, L. (2004). The development of children's expressive drawing. British Journal of Developmental Psychology, 22(4), 545-567. https://doi.org/10.1348/0261510042378236

Kärnä, P., Hakonen, R., \& Kuusela, J. (2012). Luonnontieteellinen osaaminen perusopetuksen 9. luokalla 2011. Tampere: Opetushallitus.

Kohonen, I., Kuula-Luumi, A., \& Spoof, S. K. (2019). The ethical principles of research with human participants and ethical review in the human sciences in Finland. Finnish National Board on Research Integrity TENK guidelines 2019. Helsinki, Finland: TENK. Retrieved from

https://www.tenk.fi/sites/tenk.fi/files/Ihmistieteiden_eettisen_ennakkoarvioinnin_ohje_2 019.pdf

Kress, G. R. (2010). Multimodality: A Social Semiotic Approach to Contemporary Communication. New York: Routledge.

Kuttner, P. J., Sousanis, N., \& Weaver-Hightower, M. B. (2017). How to draw comics the scholarly way. In P. Leavy (Ed.), Handbook of Arts-Based Research (pp. 396-422). Guilford Publications.

Lamminpää, J., Vesterinen, V., \& Puutio, K. (2020). Draw-A-Science-Comic: exploring children's conceptions by drawing a comic about science. Research in Science \& Technological Education, $O$ O(oo), 1-22. https://doi.org/10.1080/02635143.2020.1839405

Lederman, J. S., Lederman, N. G., Bartos, S. A., Bartels, S. L., Meyer, A. A., \& Schwartz, R. S. (2014). Meaningful assessment of learners' understandings about scientific inquiry - The views about scientific inquiry (VASI) questionnaire. Journal of Research in Science Teaching, 51(1), 65-83. https://doi.org/10.1002/tea.21125

Losh, Susan C., Wilke, R., \& Pop, M. (2008). Some methodological issues with "Draw a Scientist Tests” among young children. International Journal of Science Education, 30(6), 773-792. https://doi.org/10.1080/09500690701250452 
Losh, Susan Carol. (2010). Stereotypes about scientists over time among US adults: 1983 and 2001. Public Understanding of Science, 19(3), 372-382.

https://doi.org/10.1177/0963662508098576

Maltese, A. V., \& Tai, R. H. (2011). Pipeline persistence: Examining the association of educational experiences with earned degrees in STEM among U.S. students. Science Education, 95(5), 877-907. https://doi.org/10.1002/sce.20441

Maoldomhnaigh, M., \& Hunt, Á. (1988). Some Factors Affecting the Image of the Scientist Drawn by Older Primary School Pupils. Research in Science \& Technological Education, 6(2), 159166. https://doi.org/10.1080/0263514880060206

McCarthy, D. (2015). Teacher candidates' perceptions of scientists: images and attributes. Educational Review, 674), 389-413. https://doi.org/10.1080/00131911.2014.974510

McCloud, S. (1994). Understanding Comics: The Invisible Art. HarperPerennial. Retrieved from https://books.google.fi/books?id=oJ1vPwAACAAJ

Miele, E. (2014). Using the Draw-a-Scientist Test for Inquiry and Evaluation. Journal of College Science Teaching, 43(4), 36-40. https://doi.org/10.2505/4/jcst14_043_04_36

Miller, D. I., Nolla, K. M., Eagly, A. H., \& Uttal, D. H. (2018). The Development of Children's Gender-Science Stereotypes: A Meta-analysis of 5 Decades of U.S. Draw-A-Scientist Studies. Child Development, oo(o), 1-13. https://doi.org/10.1111/cdev.13039

National Science Board. (2002). Science and engineering indicators 2002 (Vol. 1). Arlington, VA: National Science Foundation.

Oktay, O., \& Eryurt, K. (2012). How High School Students Represent the Image of Scientists in their Minds. Procedia - Social and Behavioral Sciences, 46, 2482-2486.

https://doi.org/10.1016/j.sbspro.2012.05.507

Prosser, J., \& Burke, C. (2008). Image-Based Educational Research: Childlike Perspectives. In J. G. Knowles \& A. L. Cole (Eds.), Handbook of the Arts in Qualitative Research: Perspectives, Methodologies, Examples, and Issues (1st ed., Vol. 4, pp. 407-420). Thousand Oaks, California: SAGE Publications Ltd. https://doi.org/10.4135/9781452226545

Rahm, J., \& Charbonneau, P. (1997). Probing stereotypes through students' drawings of scientists. American Journal of Physics, 65(8), 774-778. https://doi.org/10.1119/1.18647

Reinisch, B., Krell, M., Hergert, S., Gogolin, S., \& Krüger, D. (2017). Methodical challenges concerning the Draw-A-Scientist Test: a critical view about the assessment and evaluation of learners' conceptions of scientists. International Journal of Science Education, 39(14), 1952-1975. https://doi.org/10.1080/09500693.2017.1362712

Reis, P., \& Galvao, C. (2004). Socio-scientific controversies and students' conceptions about scientists. International Journal of Science Education, 26(13), 1621-1633. https://doi.org/10.1080/0950069042000205413

Symington, D., \& Spurling, H. (1990). The 'Draw a Scientist Test': interpreting the data. Research in Science \& Technological Education, 8(1), 75-77. https://doi.org/10.1080/0263514900080107

Türkmen, H. (2008). Turkish primary students' perceptions about scientist and what factors affecting the image of the scientists. Eurasia Journal of Mathematics, Science and Technology Education, 4(1), 55-61.

Vidgen, B., \& Yasseri, T. (2016). P-Values: Misunderstood and Misused. Frontiers in Physics, 4(March), 10-14. https://doi.org/10.3389/fphy.2016.00006

Walls, L. (2012). Third grade African American students' views of the nature of science. Journal of Research in Science Teaching, 49(1), 1-37. https://doi.org/10.1002/tea.20450

Yuen, F. C. (2004). "It was fun... I liked drawing my thoughts": Using drawings as a part of the focus group process with children. Journal of Leisure Research, 36(4), 461-482.

https://doi.org/10.1080/00222216.2004.11950032 